Presented at 2nd IEEE International NanoElectronics Conference,

3-8 January 2010, Hong Kong, China

\title{
Roll to roll fabrication of thin film silicon solar cells on nano-textured substrates.
}

W.J. Soppe ${ }^{1, *}$, H. Borg ${ }^{2}$, B.B. Van Aken ${ }^{1}$, C. Devilee ${ }^{1}$, M. Dörenkämper ${ }^{1}$, M. Goris ${ }^{1}$, M.C.R. Heijna $^{1}$, J. Löffler $^{1}$, P. Peeters ${ }^{2}$

1: ECN Solar Energy, P.O. Box 1, 1755 ZG Petten, the Netherlands

E-mail: soppe@ecn.nl

2: OM\&T BV, Building SFH, Kastanjelaan 1000, 5616 LZ Eindhoven, The Netherlands 
Presented at 2nd IEEE International NanoElectronics Conference,

3-8 January 2010, Hong Kong, China

\begin{abstract}
ECN is developing a novel fabrication process for thin film silicon solar cells on steel foil. Key features in this process are: 1) application of an insulating barrier layer which enables monolithic interconnection and texturization of the rear contact with submicron structures for light trapping; 2) Si deposition with remote, linear PECVD; 3) series interconnection by laser scribing and printing after deposition of all layers, which reduces the total number of process steps. The barrier layer is essential for the monolithic series interconnection of cells, but we show that it also enables optimum light trapping in the solar cells. We can fabricate any arbitrary sub-micron surface profile by hot embossing the barrier layer. For deposition of doped and intrinsic silicon layers we use novel remote, linear plasma sources, which are excellently suited for continuous roll-to-roll processing. We have been able to fabricate device-quality amorphous and microcrystalline silicon layers with these sources. The first nip a-Si cells were made on steel substrates with flat barrier layer and had initial efficiencies of $6.5 \%$, showing the potential of the concept.
\end{abstract}


Presented at 2nd IEEE International NanoElectronics Conference,

3-8 January 2010, Hong Kong, China

\section{INTRODUCTION}

Roll-to-roll production of thin film Si solar cells has several advantages over batch-type reactor systems, for instance high-throughput fabrication and the opportunity to make lightweight and flexible products. Flexible and lightweight PV modules gear up to building integrated PV: the most important market for PV in densely populated, developed countries $[1,2]$. ECN is developing a pilot line for roll-to-roll production of high efficiency n-i-p solar cells based on amorphous (a-Si:H) and microcrystalline ( $\mu \mathrm{c}-\mathrm{Si}: \mathrm{H})$ silicon thin films on steel foil coated with an insulating barrier layer and sputtered back contact and reflection layer. The main purpose of the barrier layer on the steel foil is to enable monolithic series interconnection of cells, to be obtained by combining depth selective laser scribing and screen printing [3]. The cell and module design of the ECN concept is depicted in Fig.1.

An important additional feature of the barrier layer as applied by ECN is that it allows nanoscale texturization through imprinting. This nano-texturization offers huge opportunities for creating light-scattering back reflectors that increase the trapping of light in the solar cells. For thin film silicon solar cells, in particular if microcrystalline silicon is used as absorber material, light trapping is of uppermost importance because of the relative weak absorption of this material. In principle, any arbitrary structure can be fabricated by this texturization method, but in this paper we confine ourselves to one- and two-dimensional periodic structures.

A common benchmark for light scattering structures is the so called Lambertian scatterer [4]. This theoretical scatterer is characterized by a cosine angular distribution of the scattered light, and is considered as an ideal scatterer for thin film solar cells. Periodic gratings, however, have been shown to be able to outperform the Lambertian scatterer - at least in theory - provided that the correct periodicity and aspect ratios are chosen [5]. 
Presented at 2nd IEEE International NanoElectronics Conference,

3-8 January 2010, Hong Kong, China

Up to now, most of the research activities in this field have been focused on light management techniques for p-i-n thin film silicon solar cells (the superstrate concept) in which the TCO layer on the front side of the cell is textured $[6,7,8,9,10]$. The $p$, $i$ and n-type silicon layers which are subsequently deposited on the textured TCO layer, are assumed to "follow" this structure but in practice the texture will fade out, leading to less pronounced texture at the bottom of the cell.

In the case of nip cells on opaque substrates, alternative strategies have to be applied. The approach that we report in this paper consists of nano-imprinting of a barrier layer that is applied on the substrate. In our case, we use steel foil as substrate, and the barrier layer also serves as an electrically insulating layer. The concept is nonetheless also applicable for other substrate concepts (using PEN, PET or polyimide foil) or even for the superstrate concept since the barrier layer that we apply is optically transparent.

After nano-imprinting of the barrier layer and subsequent deposition of the metallic back contact, this structured back contact organizes the texture of the n,i p-type silicon layers that are deposited afterwards. Our substrate concept has several (theoretical) advantages and disadvantages with respect to the superstrate concept. These follow from the fact that in the superstrate concept the highest aspects ratios of the texture will be found at the front side of the cell whereas in the substrate concept the texture at the rear side has the highest aspect ratios. A potential disadvantage of the substrate concept is that the growth of micro-crystalline silicon on textures with high-aspect ratios may lead to formation of cracks and voids $[11,12]$, so extra pre-cautions have to be made to avoid the formation of these defects in the bottom of the cell. A superstrate tandem cell concept, with an amorphous top cell would be less vulnerable for this defect formation. A potential advantage of the substrate concept, with less pronounced texture at the front side of the cell, is that the $\mathrm{p} / \mathrm{i}$ area is less expanded, leading to less leak current and higher $\mathrm{V}_{\mathrm{oc}}$ than for the superstrate concept. 
Presented at 2nd IEEE International NanoElectronics Conference,

3-8 January 2010, Hong Kong, China

So far, these are all theoretical considerations which still need to be validated by modeling and by real device fabrication. In the EU FP7 project Silicon-light, which will start by January 1, 2010 both the theoretical and the experimental route will be followed to investigate these topics into more detail.

\section{APPROACH}

A. Application and nano-imprinting of barrier layer on steel foil

Our concept for monolithic series interconnection, using steel foil as substrate, requires a uniform, pinhole-free barrier layer, with sufficient electrical resistance; the typical breakdown voltage should be higher than $1000 \mathrm{~V}$. The insulating barrier layer that we use consists of a heat-curing $\mathrm{SiO}_{\mathrm{x}}$-polymer sol-gel coating that can by applied by either roll coating or spray coating. After application, the layer is dried for a short time until the surface is dust-dry but the bulk of the layer is still plastically deformable. The dried layer thickness is in the range of 5-10 micron. At this point, a texture can be applied to the sol-gel layer by nano-imprint lithography (see Fig. 2).

For our batch-type laboratory tests a master of up to $25 \mathrm{~cm}^{2}$ is placed on top of the coated steel foil with its texture towards the barrier layer. The texture is applied by a hydraulic press with heated anvils, resulting in the inverse of the original surface morphology. Several metal master structures, with diffraction gratings for 1-D and 2-D periodic structures were tested for their replication and optical properties. Due to the (lightly) dried surface of the sol-gel layer, an anti-sticking layer is not required on the masters.

\section{B. Characterization of the texture}

Feature sizes of masters and replicas of the 1-D and 2-D periodic textures were measured by 
Presented at 2nd IEEE International NanoElectronics Conference,

3-8 January 2010, Hong Kong, China

SEM (JEOL 6330F) and AFM (Digital Instruments Nanoscope)

Next to standard optical reflection measurements with an integrating sphere, to determine the haze factor as a function of the wavelength of the incident light, we determined the angular dependent scattering of the periodic structures using an Imaging Sphere (IS-SA) from Radiant Imaging Inc. The IS-SA system consists of a 20" diameter, hemispherical measurement dome, mated with an Imaging Colorimeter (with a $512 \times 512$ CCD pixel detector). The IS-SA is equipped with a white light illumination source $(400-800 \mathrm{~nm})$ and acquires data over an entire $2 \pi$ steradian in a single measurement, taking just seconds.

\section{Cell fabrication}

Fabrication of nip a-Si solar cells on nano-textured substrates consisted of the following steps. The textured substrates, made as described in the previous section obtained a $\mathrm{ZnO} / \mathrm{Ag}$ stack back contact by sputtering. Subsequently n, i and p-type Si layers were deposited in PECVD systems equipped with VHF plasma sources. For these experiments we used small substrates of $10 \times 2.5 \mathrm{~cm}^{2}$ which were attached to the carrier substrate. After deposition of the Si layers, a top TCO consisting of $80 \mathrm{~nm}$ ITO, or $540 \mathrm{~nm} \mathrm{ZnO:Al} \mathrm{was} \mathrm{sputtered,} \mathrm{while} \mathrm{a} \mathrm{mask} \mathrm{was} \mathrm{used}$ to define $4 \times 4 \mathrm{~mm}^{2}$ cells. Finally we evaporated $\mathrm{Ag}$ front contact grids.

\section{RESULTS}

\section{A. Nanotexturization}

1D and 2D periodically textured nickel master plates ware manufactured by photolithographic processes, using equipment that is commonly applied for DVD master manufacturing.

Figure 3 shows SEM images of a metal master with a periodic one-dimensional diffraction grating and its replica. This and other tested gratings consist of U-shaped grooves of $300 \mathrm{~nm}$ 
Presented at 2nd IEEE International NanoElectronics Conference,

3-8 January 2010, Hong Kong, China

deep, with periods of 500, 750 and $1000 \mathrm{~nm}$. For all three periods, the replicas compare well with their originals, as can be observed e.g. in Figure 4, in which an AFM section analysis of a replica of the 1-D grating with period of $1000 \mathrm{~nm}$ is plotted. The same holds for the 2-D periodic textures, as shown in Figure 5, where the deviations of pitch and depth between original and replica are in the same range as the error margins of the AFM measurements.

\section{B. Optical characterization}

Measurements of the haze, i.e. the ratio between diffuse and total reflection, of the 1-D metal masters and Al-covered replicas are shown in Figure 6. At wavelengths $\lambda$ lower than the grating's period $\mathrm{p}$, diffraction occurs at an angle $\sin \theta=\lambda / \mathrm{p}$. For longer wavelengths no diffraction occurs and all light is specularly reflected. Qualitatively the haze of the masters and Al-covered replicas match, but quantitatively there are deviations due to the different dielectric functions.

BRDF measurements of the 1-D grating with period $750 \mathrm{~nm}$ are shown in Figure 7 . In accordance with theory strong first order diffraction maxima are observed at - and +45 degrees for normal incident light (Figure 7-a). The difference in the intensities between the two peaks can be explained by the slight curvature of the grating (due to the DVD mastering technology). The specular reflection (or zero ${ }^{\text {th }}$ order) is not visible as it is caught by the incident light beam entry port. Changing the angle of the incident light to 45 degrees (Figure 7-b) reveals also the zero ${ }^{\text {th }}$ and higher order diffraction peaks of this 1-D grating.

BRDF measurements of the 2-D grating are shown in Figure 8. We see that the diffraction pattern has a six-fold symmetry where one would expect a four-fold symmetry for a pure rectangular 2-D grating. As mentioned before, the 2-D pattern that we have applied deviates slightly from rectangular and this deviation is the cause of the additional first order diffraction peaks. The figure also shows that the higher order diffraction peaks are much weaker than for 
Presented at 2nd IEEE International NanoElectronics Conference,

3-8 January 2010, Hong Kong, China

the 1-D grating and this can be attributed to the wiggle-shaped structure causing some loss of the long range periodicity.

\section{Solar cells}

So far, the best cell results were obtained using ITO as front TCO. For flat substrates we achieved cell efficiencies up to $6.3 \%$, with a $\mathrm{V}_{\mathrm{oc}}$ of $840 \mathrm{mV}$ and a $\mathrm{J}_{\mathrm{sc}}$ of $14.1 \mathrm{~mA} / \mathrm{cm}^{2}$. Cells on periodically textured substrates have, up to now, only been fabricated with $\mathrm{ZnO}$ :Al as top TCO. The interface between p-layer and $\mathrm{ZnO}: \mathrm{Al}$, however, leads to a barrier for charge carrier collection and needs further optimization. The efficiencies of cells with a periodically textured back contact therefore are still moderate, but proof the feasibility of the concept. Best cells were obtained for a periodic grating of $750 \mathrm{~nm}$; yielding $\mathrm{V}_{\mathrm{oc}}=800 \mathrm{mV}$ and $\mathrm{J}_{\mathrm{sc}}=11 \mathrm{~mA} / \mathrm{cm}^{2}$.

\section{CONCLUSIONS}

ECN is developing a novel fabrication process for thin film silicon solar cells on foil. Steel foil is a suitable substrate and when a proper barrier layer is applied, monolithic series interconnection of cells can be accomplished in one process step after deposition of all functional layers. We have shown that defined sub-micron structures can be applied to this barrier layer by nano-imprinting, and that this texturization method will contribute significantly to enhanced light-trapping in the solar cells. Bi-directional Distribution Functions of the light scattering of 1- and 2-D periodic gratings were obtained quick and effectively by a new instrument: the Radiant Imaging Sphere. We were able to fabricate nip aSi solar cells, on steel foil + barrier layer, with efficiencies $6.3 \%$, demonstrating the feasibility of the concept.

\section{ACKNOWLEDGMENT}


Presented at 2nd IEEE International NanoElectronics Conference,

3-8 January 2010, Hong Kong, China

This work has been financially supported by the EU (Flexcellence project EU FP-6 Energy 2004 - 019948), and by the Dutch Ministry of Economic Affairs (contracts TSIN3043 and EOSLT04029). We wish to thank Olindo Isabella, Martijn Tijssen and Miro Zeman from Delft University of Technology for their contribution to the fabrication of nip a-Si solar cells on coated steel foil. 
Presented at 2nd IEEE International NanoElectronics Conference, 3-8 January 2010, Hong Kong, China

\section{REFERENCES}

1. M. Izu and T. Ellison, Sol. En. Mat. Sol. Cells 78, 613 (2003).

2. A. Takano and T. Kamoshita, Jap. J. Appl. Phys. 43, 7976 (2004).

3. J. Löffler, L.A. Wipliez, M.A. de Keijzer, J. Bosman, W.J. Soppe, 34th IEEE

Photovoltaic Specialists Conference, Philadelphia, June 2009.

4. J. Krc, M. Zeman, O. Kluth, F. Smole, M. Topic, Thin Solid Films 426, 296 (2003).

5. M.M. Jakas and F. Llopes, International Journal of Sustainable Energy, 29, 1 (2010).

6. J. Krc, M. Zeman, F. Smole and M. Topic, J. Appl. Phys. 92, 739 (2002).

7. H. Stiebig, N. Senoussaoui, T. Brammer and J. Müller, Sol. En. Mat. 90, 3031 (2006).

8. N. Senoussaoui, M. Krause, J. Müller, E. Bunte, T. Brammer and H. Stiebig, Thin Solid Films 451, 397 (2004).

9. A.J.M. van Erven, et al., presented at the $23^{\text {rd }}$ EPVSEC, 1-5 September 2008, Valencia, Spain.

10. R. Dewan and D. Knipp, J. Appl. Phys. 106, 074901 (2009).

11. T. Söderström, F.-J. Haug, V. Terrazzoni-Daudrix, and C. Ballif, J. Apl. Phys. 103, 114509 (2008)

12. M. Python, "Microcrystalline silicon solar cells: growth and defects", Thesis, University of Neuchatel, 2008. 


\section{FIGURES}

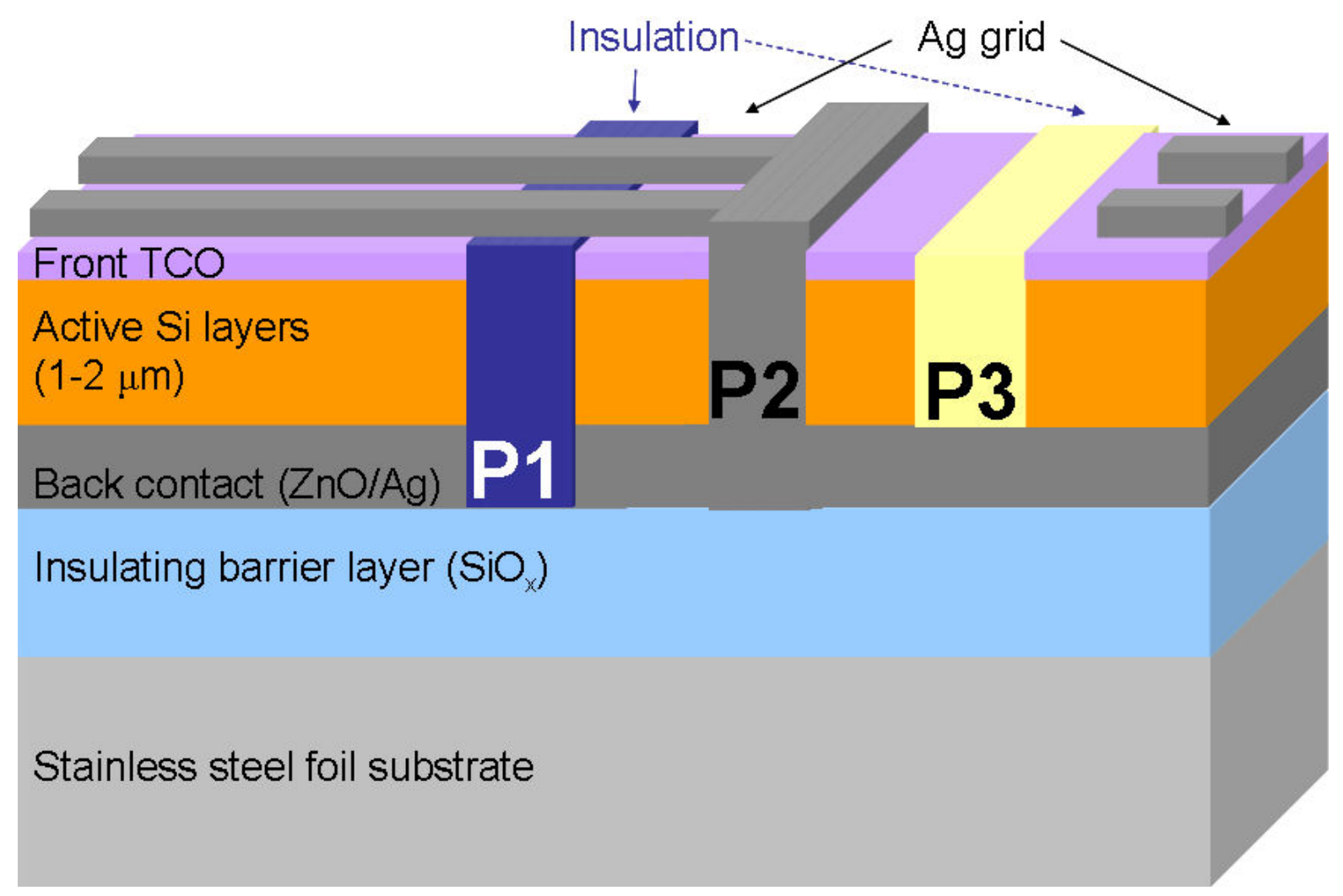

Figure 1. Cell and module layout. Typical thickness of the steel foil is 75 micron. The thickness of the barrier layer is between 5 and 10 micron. The back contact consists of a $\mathrm{Ag}$ layer of about $80 \mathrm{~nm}$ plus a $\mathrm{ZnO}$ layer of about $250 \mathrm{~nm}$. The front $\mathrm{TCO}$ is either $\mathrm{ZnO}$ :Al with a thickness about $500 \mathrm{~nm}$ or an ITO layer with a thickness of $80 \mathrm{~nm}$. P1, P2 and P3 are laser scribes for monolithical series connection. P1 is filled with an insulating paste, whereas P2 is filled with a conductive paste, bridging the front contact of the cell on the left side with the back contact of the cell on the right side of the scribes. 
Presented at 2nd IEEE International NanoElectronics Conference,

3-8 January 2010, Hong Kong, China
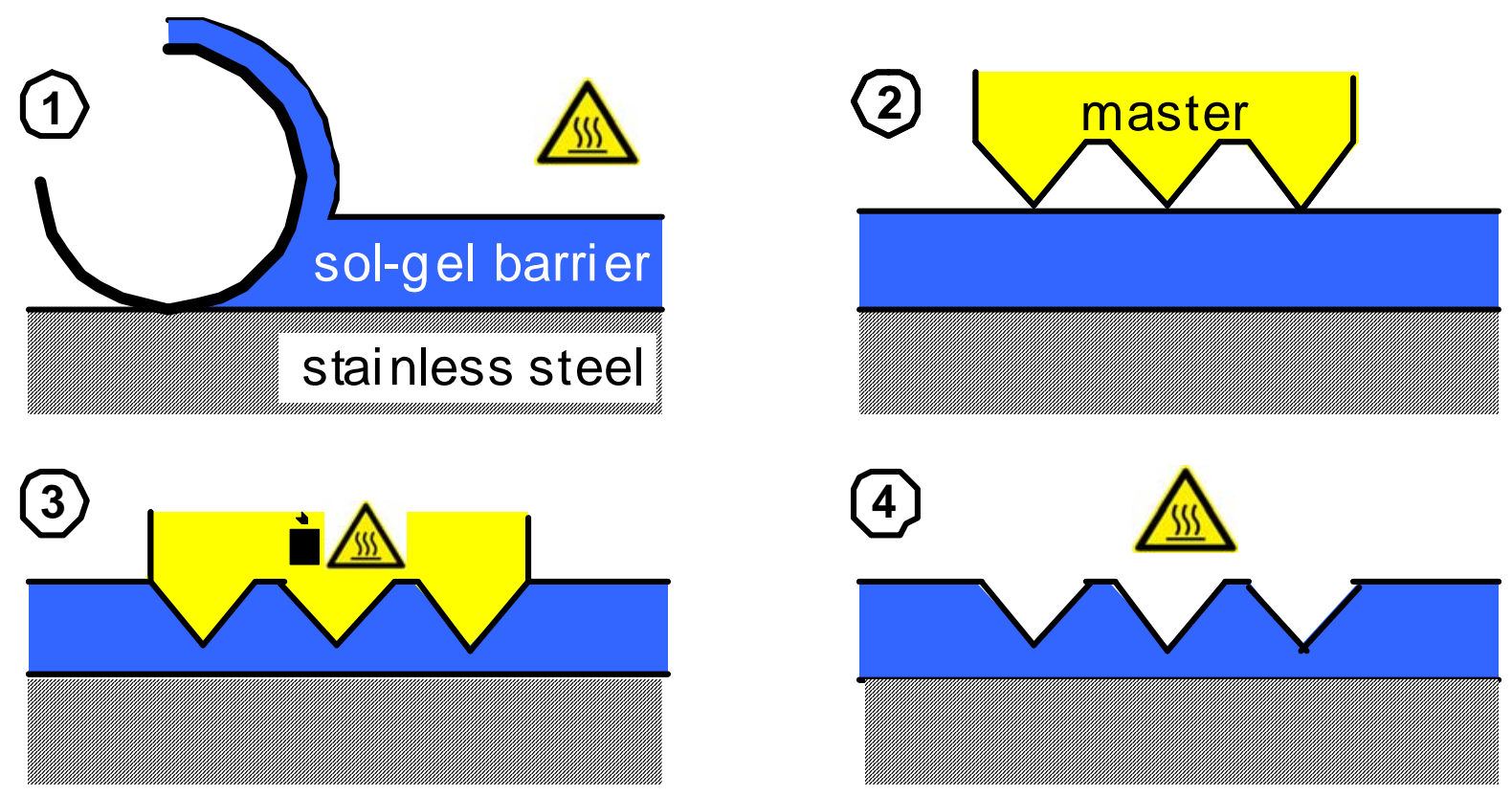

Figure 2. Schematic process steps for hot embossing. 

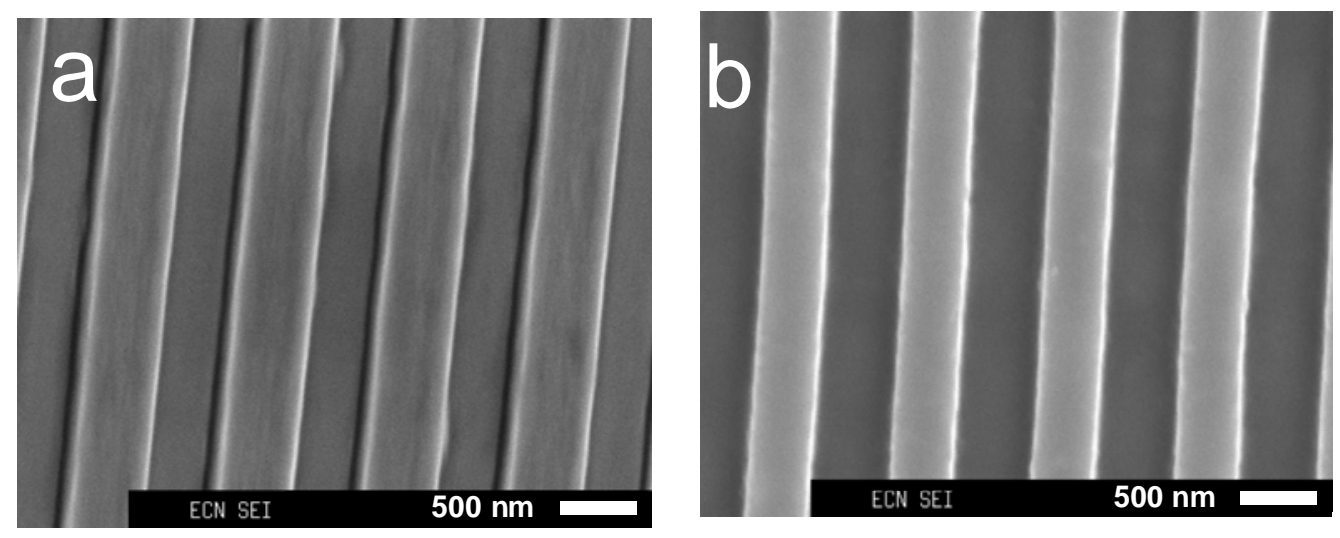

Figure 3: SEM images of a metal master with a $1000 \mathrm{~nm} 1 \mathrm{D}$ period grating (a) and its replica in the sol-gel barrier layer (b). The scale bar in both images represents $500 \mathrm{~nm}$. 
Presented at 2nd IEEE International NanoElectronics Conference,

3-8 January 2010, Hong Kong, China

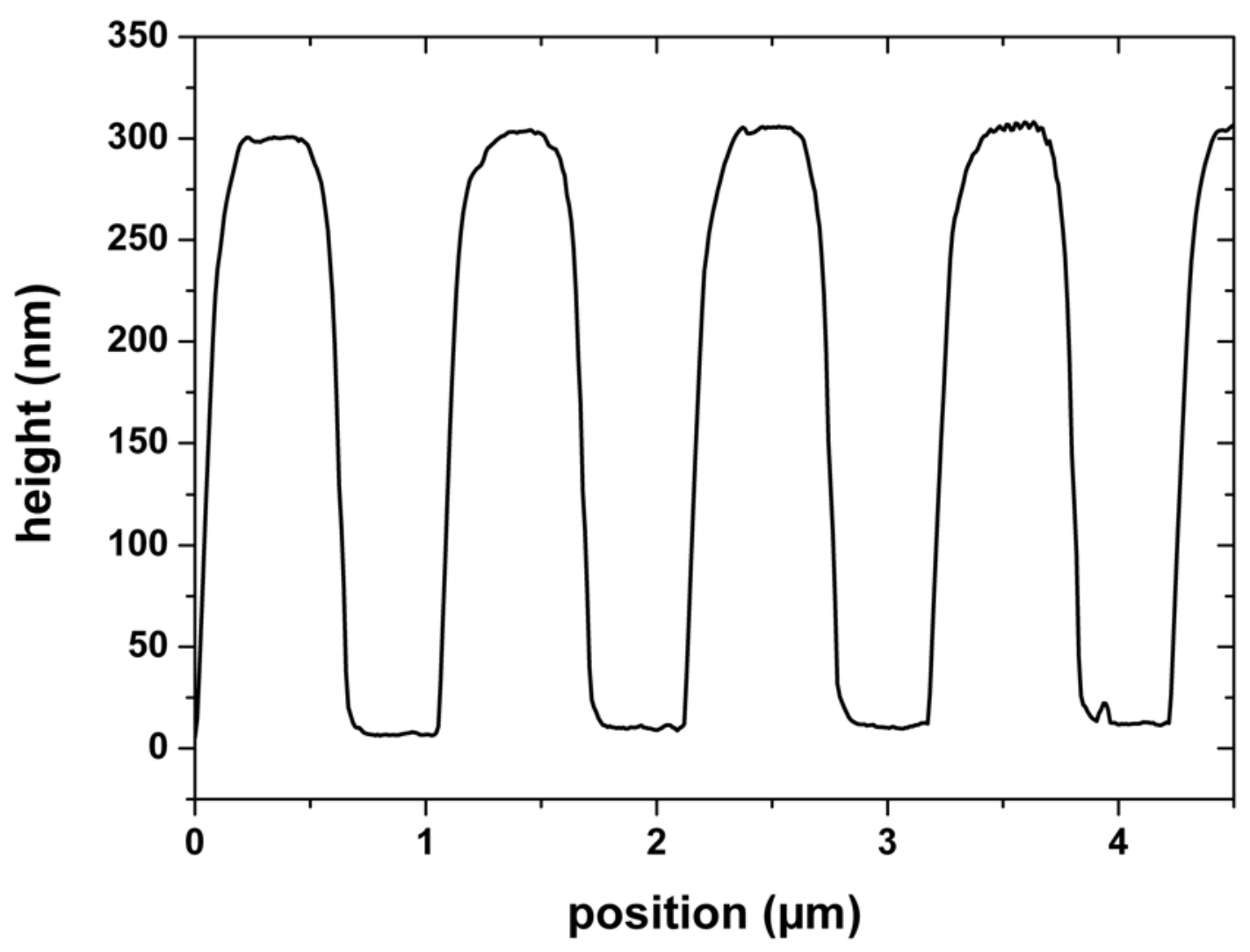

Figure 4: Section analysis by AFM of a replica of a 1-D periodic structure with nominal track pitch of $1000 \mathrm{~nm}$ and depth of $300 \mathrm{~nm}$. The depth of the replica structure is about $295 \mathrm{~nm}$ and the valley width is about $500 \mathrm{~nm}$. 

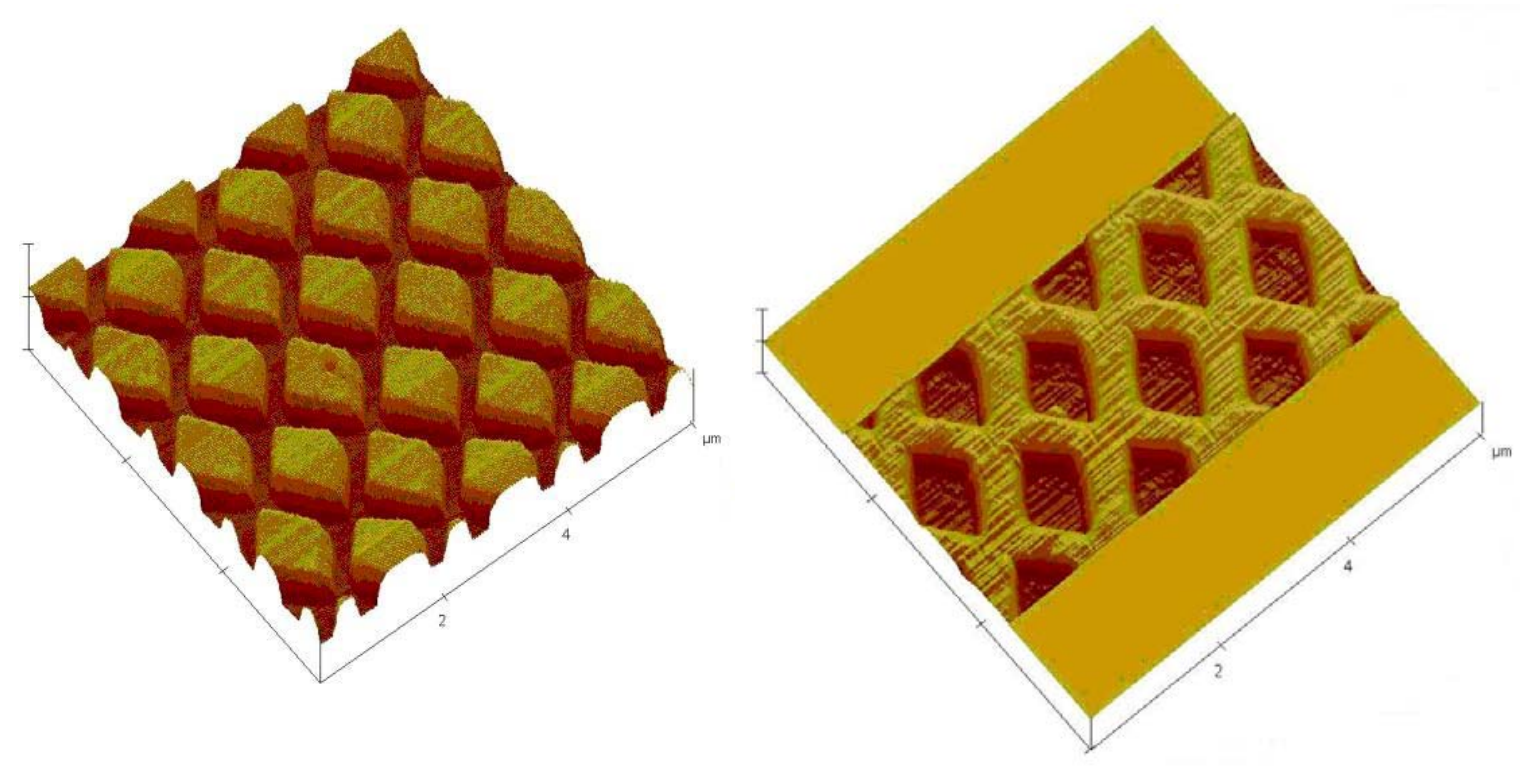

Figure 5: AFM measurements of Master and Replica of 2-D periodic textures, with a nominal track pitch of $900 \mathrm{~nm}$ and a depth of $300 \mathrm{~nm}$. For the Master (left) the depth of the texture is $274 \mathrm{~nm}$, and the track pitch is $891 \mathrm{~nm}$. For the Replica the depth of the texture is $312 \mathrm{~nm}$ and the track pitch is $879 \mathrm{~nm}$. 
Presented at 2nd IEEE International NanoElectronics Conference,

3-8 January 2010, Hong Kong, China

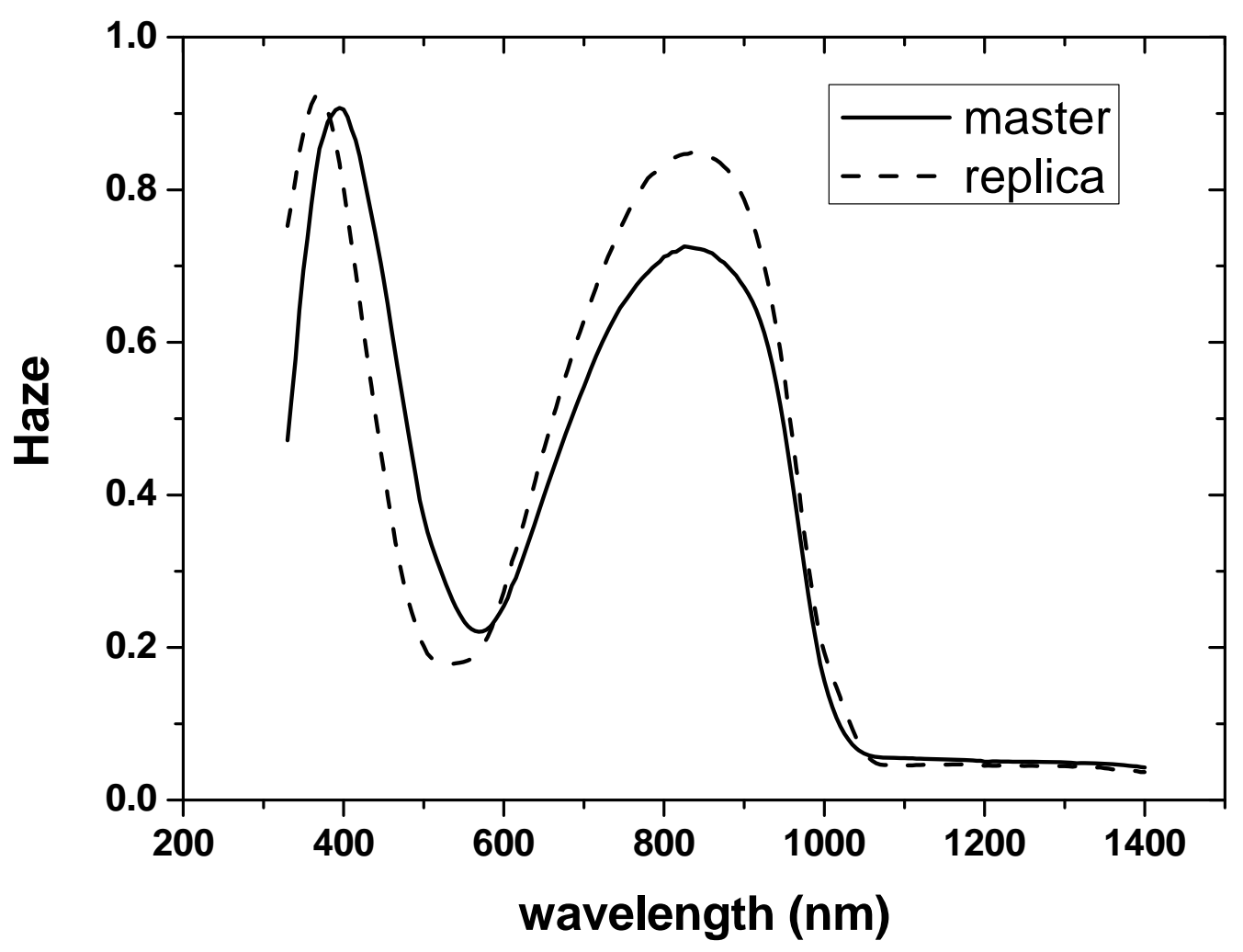

Figure 6. Haze measurements on master and replicas with 1-D diffraction grating of $1000 \mathrm{~nm}$. 
Presented at 2nd IEEE International NanoElectronics Conference,

3-8 January 2010, Hong Kong, China

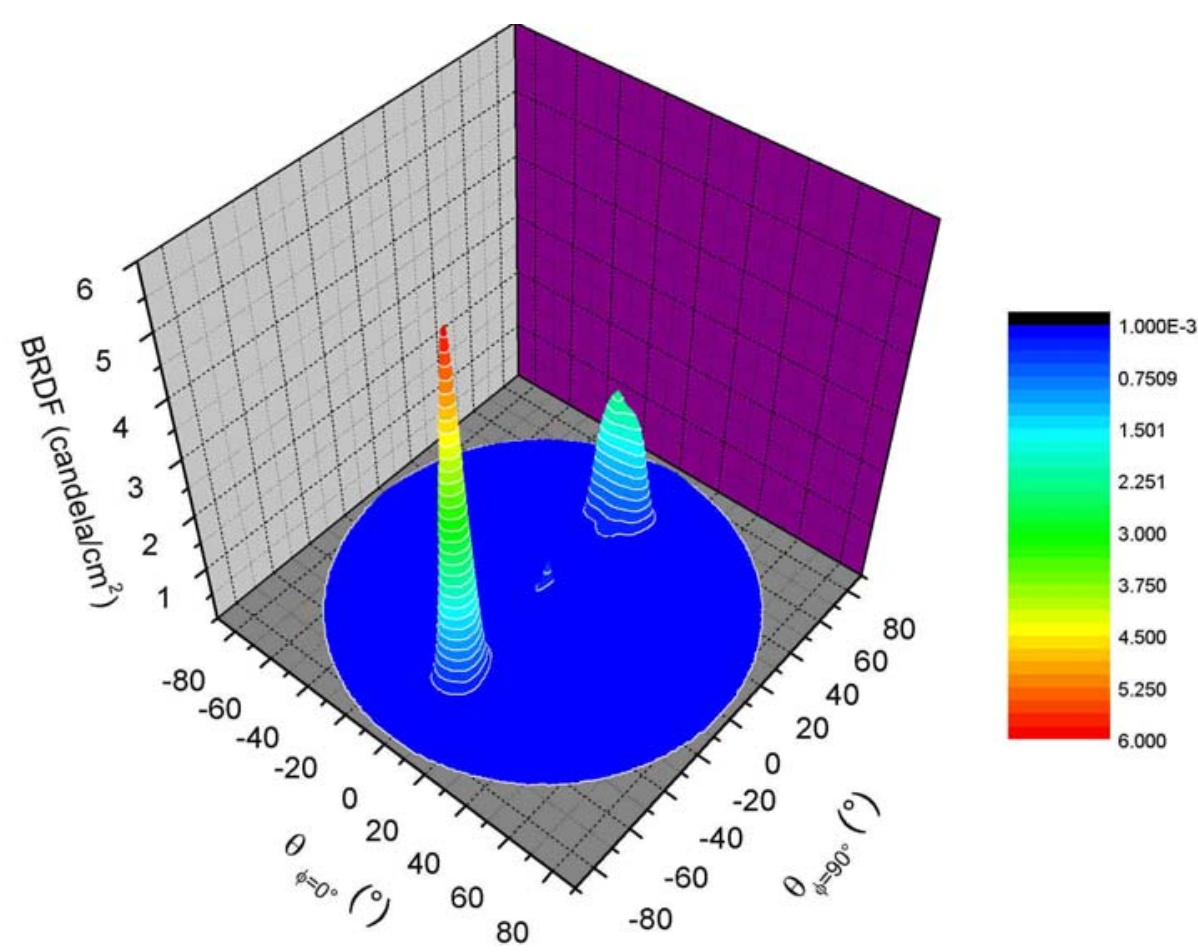

a

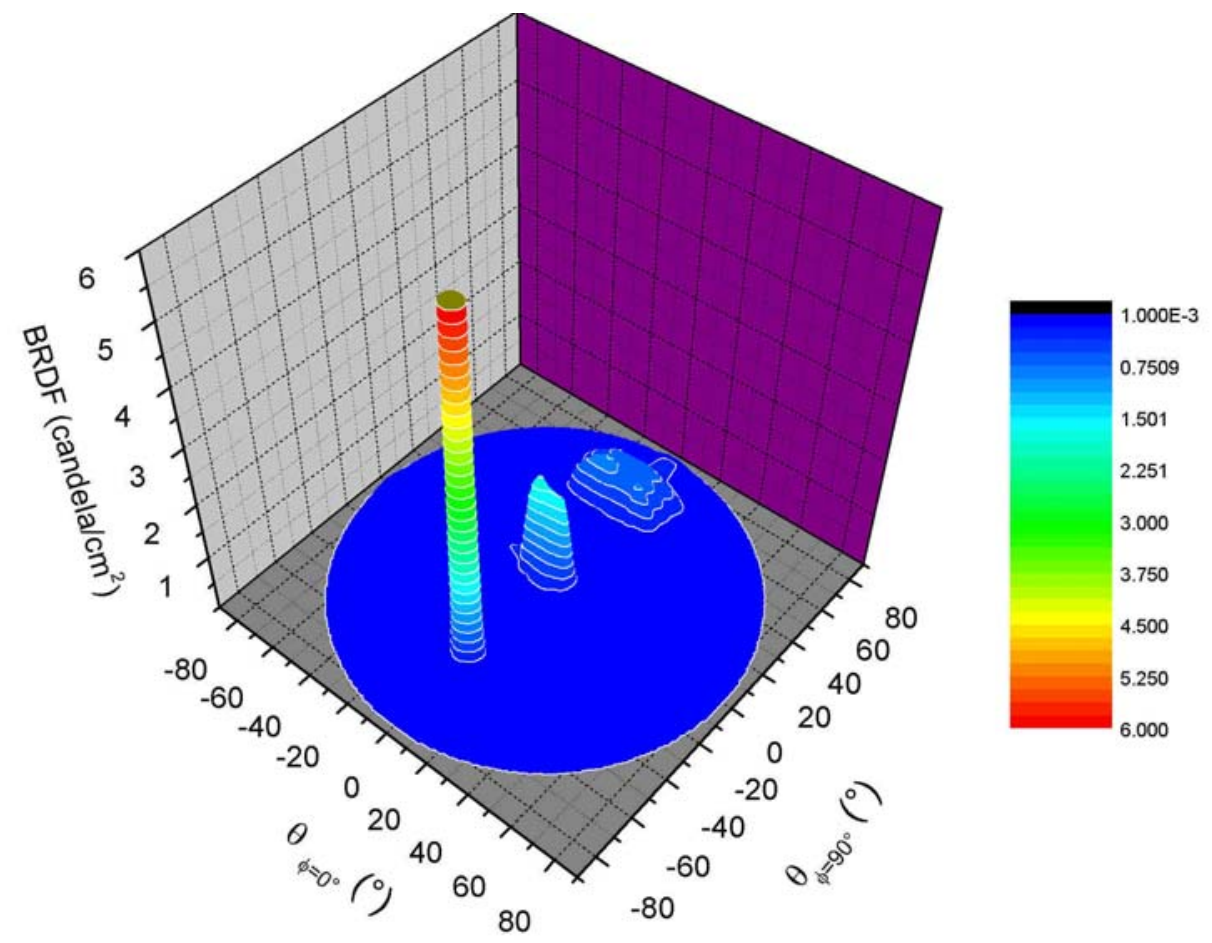

b 
Presented at 2nd IEEE International NanoElectronics Conference,

3-8 January 2010, Hong Kong, China

Figure 7: Bidirectional Reflection Distribution Function for the scattering of a 1-D periodic grating with incident light angle of respectively 0 (a) and 45 degrees (b) with respect to the normal. 
Presented at 2nd IEEE International NanoElectronics Conference,

3-8 January 2010, Hong Kong, China

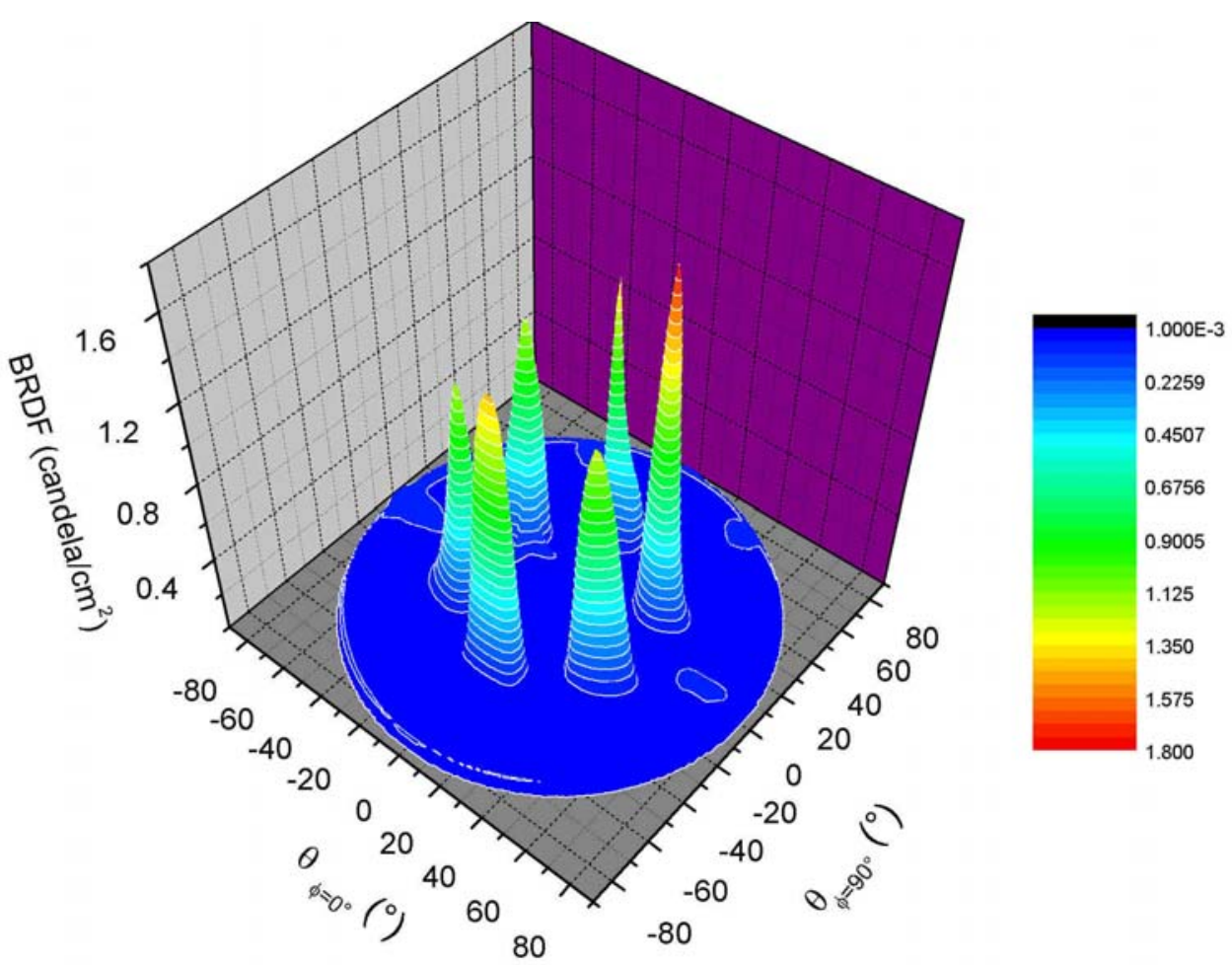

a

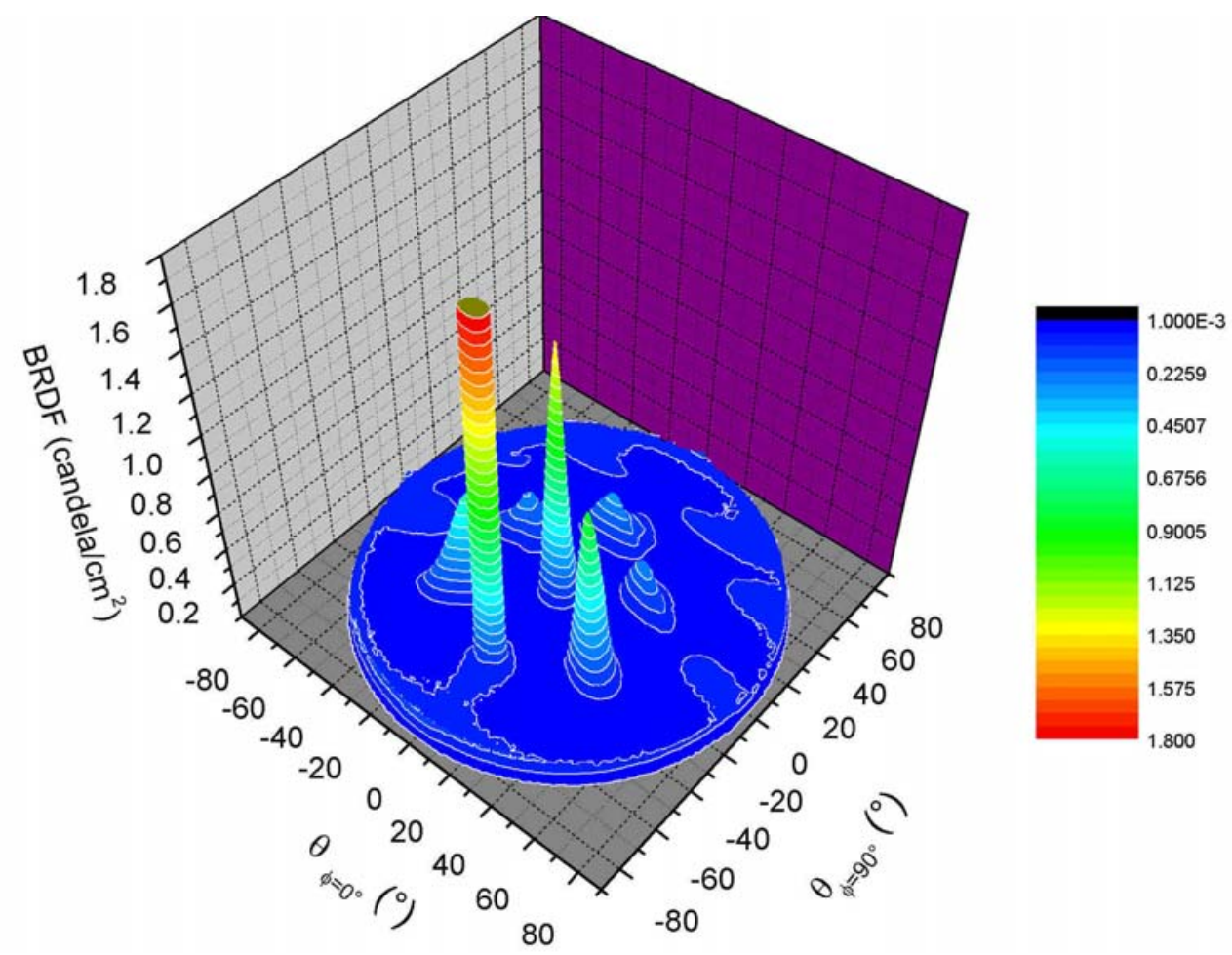


Presented at 2nd IEEE International NanoElectronics Conference,

3-8 January 2010, Hong Kong, China

b

Figure 8: Bidirectional Reflection Distribution Function for the scattering of a 2-D periodic grating with incident light angle of respectively 0 (a) and 45 degrees (b) with respect to the normal. 